ORIGINAL ARTICLE

\title{
Does oral contraceptive use affect maximum force production in women?
}

\author{
K J Elliott, N T Cable, T Reilly
}

Br J Sports Med 2005;39:15-19. doi: 10.1136/bjsm.2003.009886

See end of article for authors' affiliations

.....................

Correspondence to: Dr K Elliott, University of Brighton, 12 Greendale Close, Fareham PO156ES, UK; kirsty.elliott2@ btopenworld.com

Accepted 16 December 2003

\begin{abstract}
Objective: To examine the effects of oral contraceptive use on maximum force production in young women.

Methods: In the study, 21 female subjects (14 pill users and seven eumenorrheic controls) took part. All pill using subjects had been taking a combined, monophasic oral contraceptive pill for at least 6 months. Maximum dynamic and isometric leg strength, maximum isometric strength of the first dorsal interosseus (FDI) muscle, and plasma concentrations of oestradiol and progesterone were measured on days 7 and 14 of pill consumption and day 5 of pill withdrawal. The eumenorrheic group was tested (FDI strength and hormone concentrations) on days 2 and 21 of the menstrual cycle.

Results: There were no significant changes in the concentration of endogenous oestradiol or progesterone or any measure of muscle strength between pill phases $(p<0.05)$. The pill group did not significantly differ from the eumenorrheic group $(p<0.05)$, despite a significant increase in the concentration of progesterone and oestradiol on day 21 of the menstrual cycle compared with day 2 of the menstrual cycle and pill consumption and withdrawal $(p<0.05)$.

Conclusions: These data suggest that oral contraceptive use does not significantly affect muscle strength. Moreover, oral contraceptive users were not stronger or weaker than their eumenorrheic counterparts.
\end{abstract}

$\mathrm{O}$ ral contraceptives are available in single (progesterone only) and combined (oestrogen and progestogen) formulations. The oestrogenic and progestogenic content ranges from 0.02 to $0.5 \mathrm{mg}$ and 0.1 to $1.0 \mathrm{mg}$, respectively. Phasic oral contraceptives mimic the cyclical variations in endogenous hormones by only providing synthetic ovarian hormones for 21 out of 28 days. The pill acts, via negative feedback, on the hypothalamus and anterior pituitary gland, causing the suppression of follicle stimulating hormone (FSH), lutenising hormone ( $\mathrm{LH})$, and gonadotropin releasing hormone (GnRH) secretion. Subsequently, the concentration of endogenous sex hormones (oestradiol and progesterone) is reduced to levels indicative of the menopause. Several researchers have noted that adverse changes in specific muscle strength occur around the onset of menopause in women. ${ }^{1-7}$ However, it is difficult to conclude a sex hormone dependent loss in strength using the model of menopause, as it is difficult to control for other age related factors that may affect muscle strength.

Previous research examining the influence of oral contraceptive use on muscle function has been limited, as pill users have been used as a control rather than an experimental group. Sarwar et al ${ }^{8}$ found that maximum voluntary force of the quadriceps or hand muscles did not change when tested weekly over two cycles in women using oral contraception. All subjects were taking a monophasic combined pill (20$35 \mu \mathrm{g}$ of ethinyl oestradiol and progestins in different doses). These authors suggested that, as progestin levels can remain elevated for 4-5 days after ingestion, testing at variable times during the withdrawal period may have obscured their results. Similarly, Phillips et al found no significant change in maximum voluntary isometric force (MVIF) of the adductor pollicis muscle in subjects taking a non-specified pill. Conversely, Wirth and Lohman ${ }^{10}$ found significantly greater handgrip endurance times (made at 50\% of maximum voluntary contraction) and force output measurements in eumenorrheic subjects compared with pill users, despite observing no change in maximum voluntary contraction between the two groups. Eight different, non-specified pills were used in this study. However, none of these studies measured the concentration of endogenous oestradiol and progesterone during different phases of pill use; these data are needed to test the relationship between the concentration of reproductive hormones and muscle strength.

Based on the findings of post-menopausal studies, the aim of this study was to investigate whether the low levels of endogenous ovarian hormones induced by oral contraceptive use affects maximum force production in young healthy women by comparing strength measures during pill consumption (day 7 and 14) and withdrawal (day 5). It was hypothesised that maximum force production would increase during pill withdrawal, assuming that endogenous levels of oestradiol and progesterone increase during pill withdrawal as a result of the exogenous hormones being withheld. The concentration of endogenous oestradiol and progesterone was measured to support any such findings. Maximum isometric strength of the first dorsal interosseus (FDI) muscle was also tested in a group of eumenorrheic subjects so that a comparison could be made between cyclical variation (pre-menopausal) and continuous downregulation (postmenopausal) of endogenous reproductive hormone concentration. The present research design (using pill users to mimic post-menopausal hormone status) was designed to limit any potential confounding influence of age on strength assessment.

\section{METHODS \\ Subjects}

From the local university, 21 healthy, sedentary female subjects were recruited. Subjects were considered sedentary if

Abbreviations: $C$, consumption; $E F$, early follicular; $F D I$, first dorsal interosseus; $\mathrm{FSH}$, follicle stimulating hormone; $\mathrm{GnRH}$, gonadotropin releasing hormone; HRT, hormone replacement therapy; $\mathrm{LH}$, lutenising hormone; ML, mid-luteal; MVIF, maximum voluntary isometric force; $N$, maximum dynamic and isometric force of the quadriceps and hamstring muscles; $\mathrm{Nm}$, maximum voluntary isometric force of the FDI muscle; WD, withdrawal 
they were not, or had not been in the last 6 months, involved in a strength/resistance or aerobic training programme. Fourteen subjects had been taking a combined, monophasic oral contraceptive pill (standard strength) for a minimum of 6 months prior to recruitment (table 1). Combined, monophasic pills were used as they contain synthetic oestrogen and progestogen and are taken daily for 21 days, with subsequent courses taken following a 7 day interval. The remaining seven subjects reported normal menstrual cycle function, with mean cycle lengths of 29.01 (1.2) days. Only non-smokers were included in the study. ${ }^{11}$ Subjects with any muscular, neurological, or skeletal disorders capable of influencing performance of the hand or leg were excluded. Approval for the experimental protocol was obtained from the institution's human ethics committee and conformed to the Declaration of Helsinki. All subjects provided written consent, having read and understood the details of the experiment.

\section{Experimental design}

Subjects were required to abstain from alcohol and caffeine consumption and strenuous physical activity for 24 hours prior to testing to prevent known effects on reproductive hormone concentration and muscle strength. ${ }^{12-15}$ All subjects reported to the laboratory in a "normal" fed state. In order to control for circadian variation in muscle strength, ${ }^{16}$ all testing was undertaken at the same time of day. A $10 \mathrm{ml}$ venous blood sample was obtained prior to any physical testing.

The oral contraceptive users were instructed to consume their pill at 08.00 hours $( \pm 1$ hour) for the duration of the study. Prior to experimentation, subjects were familiarised, on two occasions, with the experimental environment and procedures. Following familiarisation, subjects attended the human performance laboratory in the university on three separate occasions over 2 months. Subjects were tested at 09.00 hours $( \pm 1$ hour), as peak concentrations of oestradiol and progesterone are observed in the blood $\mathrm{l} \mathrm{h}$ after consumption (Schering Health, Germany), on days 7 (7C) and $14(14 \mathrm{C})$ of pill consumption and day 5 of pill withdrawal (5WD). The exact timing of consumption and testing was noted in each case, to ensure that only 1 hour had elapsed. These phases were chosen for testing as it takes 7 days of pill consumption to completely downregulate the pituitary hormones (day 14 was used to highlight the noncyclical nature of pill consumption and confirm downregulation) and up to 5 days of withdrawal to stabilise progestin levels. ${ }^{17}$ Maximum voluntary isometric force of the FDI muscle $(\mathrm{Nm})$ and maximum dynamic and isometric force of the quadriceps and hamstring muscles $(\mathrm{N})$ were assessed as described below.

Following familiarisation, the eumenorrheic subjects were tested on two occasions: days 2 and 21 of the cycle. Day 2 (early follicular (EF) phase) was the day after the onset of menses and day 21 (mid-luteal (ML) phase) was 7 days after ovulation had occurred. The EF and the ML phases of the

\begin{tabular}{|c|c|c|c|}
\hline Pill type and manufacturer & $\mathbf{n}$ & $\begin{array}{l}\text { Oestrogen } \\
(\mu \mathrm{g})\end{array}$ & $\begin{array}{l}\text { Progestogen } \\
(\mu \mathrm{g})\end{array}$ \\
\hline $\begin{array}{l}\text { Microgynon (Schering Health, } \\
\text { Germany) }\end{array}$ & 7 & 30 & 150 \\
\hline Brevinor (Searle, USA) & 2 & 35 & 500 \\
\hline Ovarnette (Wyeth, Ireland) & 1 & 30 & 150 \\
\hline Marvalon (Organon, Ireland) & 3 & 30 & 150 \\
\hline Cilest (Janssen-Cilag Switzerland) & 1 & 35 & 250 \\
\hline
\end{tabular}

menstrual cycle were chosen for testing because the concentration of oestradiol is low and high respectively at these times, and oestradiol is the hormone most implicated in strength regulation. ${ }^{8-10}{ }^{18}$ Ovulation was determined using a urinary LH kit (Clearplan, Bedford, UK). In addition, hormonal documentation was used to confirm each phase. Maximum voluntary isometric force of the FDI muscle was also measured. Dynamic leg strength was not measured in this group, as four subjects were involved in another study involving aerobic training (running).

\section{Hormonal analysis}

Ten millilitres of venous blood were drawn from an antecubital vein into a lithium heparin coated tube by a trained phlebotomist. Samples were centrifuged at $70 \mathrm{~g}$ for 10 minutes at room temperature. Plasma was retained and stored at $-70^{\circ} \mathrm{C}$ until assayed. Total concentrations of $17-\beta$ oestradiol and progesterone were measured using an automated quantitative system (Mini Vidas, BioMerieux, France) and Vidas reagent kits (Vidas Oestradiol and Vidas Progesterone, BioMerieux, France). All samples were analysed using the ELISA technique, an enzyme immunoassay sandwich method with a final fluorescent detection.

\section{Assessment of maximum voluntary isometric force of the first dorsal interosseus muscle}

The first dorsal interosseus muscle was chosen for testing for two reasons. Firstly, the FDI muscle is the only muscle that produces abduction of the index finger. Other muscles attached to the finger are active during abduction but, because of their anatomical arrangement, they do not contribute force in this direction. Rutherford and Jones ${ }^{19}$ found very similar maximum voluntary and stimulated contraction forces for the FDI muscle, therefore demonstrating that the FDI muscle can be maximally activated and isolated from the action of other hand muscles. Secondly, these and other authors ${ }^{19}{ }^{20}$ have found no difference in force production between dominant and non-dominant hands, suggesting that this muscle is not trainable under normal conditions.

Maximal voluntary isometric force of the FDI muscle was assessed using the techniques previously described by Elliott et al. ${ }^{21}$ Three submaximal isometric contractions were carried out prior to maximum force assessment. Following a 3 minute rest, three maximum voluntary isometric contractions were performed, the best of which was taken as definitive. A 1 minute rest separated each contraction. Verbal encouragement and visual feedback was offered throughout the testing in order to promote maximum effort. Percutaneous electrical stimulation was used to superimpose electrical impulses onto the FDI muscle during each contraction. Maximum activation was confirmed when the $\mathrm{l} \mathrm{Hz}$ twitch disappeared.

\section{Maximum force assessment of the quadriceps and hamstring muscles}

Maximal voluntary isometric force of the quadriceps and hamstring muscles was assessed using the techniques previously described by Elliott et al..$^{22}$ The knee was flexed at an angle of $90^{\circ}$, using the dominant leg. Two submaximal isometric contractions were carried out prior to MVIF assessment. Following a 3 minute rest, three maximum voluntary isometric contractions were performed. A 1 minute rest separated each contraction. Subjects were tested at 1.04, 2.09, and $4.19 \mathrm{rad} / \mathrm{s}$, as these speeds test absolute to functional strength. Percutaneous electrical stimulation was used to superimpose electrical impulses onto the quadriceps muscles during each maximum voluntary isometric contraction. Two self adhesive surface electrodes $(7.6 \mathrm{~cm} \times 12.7 \mathrm{~cm}$; 
Healthcare, London, UK) delivered $50 \mathrm{~Hz}$ twitches at a tolerable current throughout the test. Individual tolerable currents were established prior to MVIF assessment and were defined as the maximum current a subject could sustain without pain or discomfort. The electrodes were positioned on the anterior aspect of the thigh, midway between the superior border of the patella and the anterior superior iliac spine and over the lateral aspect of the thigh, one handbreadth above the patella. Electrical impulses were applied, using a computer driven Digitimer stimulator (Model DS7; Digitimer Ltd, UK), at 250 V with a pulse width of $200 \mu$ s duration.

\section{Statistical analysis}

SPSS (version 10; SPSS Inc., USA) was used for data analysis. Anderson-Darling normality tests were used to establish if data were normally distributed. The level of significance was taken as $p<0.05$. A repeated measures one way analysis of variance was used to detect significant differences in maximum strength (dynamic and isometric strength of the quadriceps and hamstring muscles and isometric strength of the FDI muscle) and hormone concentration (oestradiol and progesterone) between the $5 \mathrm{WD}, 7 \mathrm{C}$, and $14 \mathrm{C}$ groups. The relationship between force and ovarian hormones was examined using Pearson's correlation coefficient on normally distributed data, and Spearman's rank correlation on nonparametric data. A Mann-Whitney $U$ test was used to detect significant differences in MVIF of the FDI muscle and hormone concentration between eumenorrheic and pill subjects.

\section{RESULTS}

The mean (SD) for age, height and weight for the pill group was $22(4)$ years, $1.5(0.03) \mathrm{m}$ and $63.3(1.3) \mathrm{kg}$. The blood sample analysis showed that there were no significant changes in the concentration of endogenous oestradiol or progesterone between pill consumption and withdrawal (figs 1, 2). The concentration of exogenous oestrogen and progestogen consumed by each subject can be seen in table 1 . Repeated measures one way analysis of variance showed no significant differences between groups (5WD, 7C, and 14C), for any of the strength variables measured (table 2). Maximum force production was not affected by oral contraceptive use. Neither hormone (oestradiol and progesterone) significantly correlated with any strength measure (table 3 ).

The mean (SD) for age, height and weight for the eumenorrheic group was 24 (5) years, 1.5 (0.02), and 64.1 (1.1) kg. The blood analysis for progesterone showed that all seven eumenorrheic subjects exceeded the $16 \mathrm{nmol} / \mathrm{l}$ limit that confirms ovulation. ${ }^{23}$ The results for the plasma hormone concentration of oestradiol and progesterone are shown in figs 1 and 2. The concentration of oestradiol and progesterone

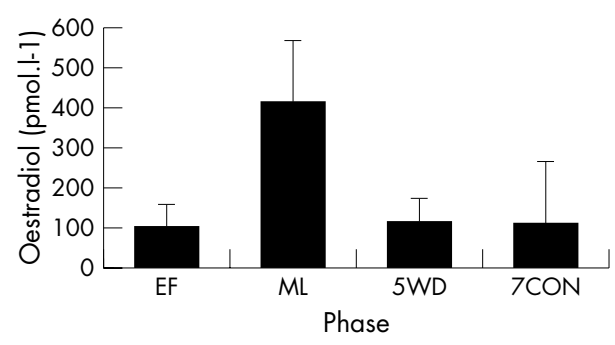

Figure 1 Plasma concentrations of oestradiol during two phases of the menstrual cycle and two phases of pill use. The columns represent the means (SD) of the hormone concentration. The ML phase was significantly different from all other phases $(p<0.05)$.

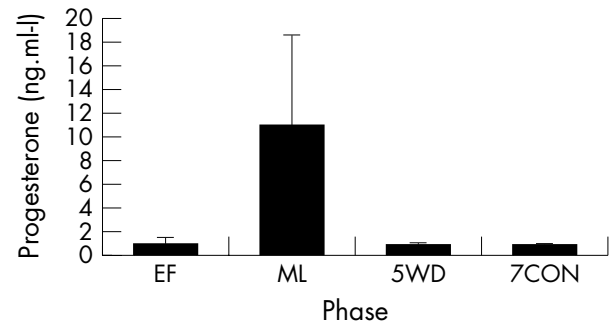

Figure 2 Plasma concentrations of progesterone during two phases of the menstrual cycle and two phases of pill use. The columns represent the means (SD) of the hormone concentration. The ML phase was significantly different from all other phases $(p<0.05)$.

Table 2 Maximum dynamic strength of the knee extensor and flexor muscles during pill withdrawal and consumption

\begin{tabular}{|c|c|c|c|}
\hline Muscle function & $\begin{array}{l}\text { Day } 5 \\
\text { withdrawal }\end{array}$ & $\begin{array}{l}\text { Day } 7 \\
\text { consumption }\end{array}$ & $\begin{array}{l}\text { Day } 14 \\
\text { consumption }\end{array}$ \\
\hline $\begin{array}{l}\text { MVIF of the FDI } \\
\text { muscle (N) }\end{array}$ & $4.56(7.41)$ & $35.18(7.16)$ & $32.12(5.80)$ \\
\hline $\begin{array}{l}\text { Isokinetic } \\
\text { extension }\end{array}$ & $132.64(19.15)$ & $139.36(22.62)$ & $126.43(32.62)$ \\
\hline $\begin{array}{l}1.04 \mathrm{rad} / \mathrm{s}(\mathrm{Nm}) \\
\text { Isokinetic flexion } \\
1.04 \mathrm{rad} / \mathrm{s}(\mathrm{Nm})\end{array}$ & $65.50(8.14)$ & $72.79(13.60)$ & 65.07 (16.94) \\
\hline $\begin{array}{l}\text { Isokinetic } \\
\text { extension }\end{array}$ & $106.86(18.88)$ & $112.07(26.20)$ & 108.21 (22.38) \\
\hline $\begin{array}{l}2.09 \mathrm{rad} / \mathrm{s}(\mathrm{Nm}) \\
\text { Isokinetic flexion } \\
2.09 \mathrm{rad} / \mathrm{s}(\mathrm{Nm})\end{array}$ & $60.29(8.38)$ & 63.57 (15.96) & $64.36(9.48)$ \\
\hline $\begin{array}{l}\text { Isokinetic } \\
\text { extension }\end{array}$ & $81.36(16.36)$ & $79.79(19.65)$ & $79.21(22.33)$ \\
\hline $\begin{array}{l}4.19 \mathrm{rad} / \mathrm{s}(\mathrm{Nm}) \\
\text { Isokinetic flexion } \\
4.19 \mathrm{rad} / \mathrm{s}(\mathrm{Nm})\end{array}$ & $55.67(13.52)$ & $57.36(13.35)$ & $53.14(13.56)$ \\
\hline $\begin{array}{l}\text { Isometric } \\
\text { extension (Nm) }\end{array}$ & $139.07(16.56)$ & $137.64(20.47)$ & $136.07(27.00)$ \\
\hline $\begin{array}{l}\text { Isometric flexion } \\
(\mathrm{Nm})\end{array}$ & 61.07 (16.34) & $60.93(18.00)$ & $56.93(17.43)$ \\
\hline
\end{tabular}

Data are shown as means (SD), $n=14$. MVIF, maximum voluntary isometric force; FDI, first dorsal interosseus muscle; ext, knee extension; flex, knee flexion. There were no significant differences between pill consumption and withdrawal for any of the variables.

were significantly higher during the ML than the the EF phase $(\mathrm{p}<0.001$ and 0.05 respectively $)$.

There were no significant differences in strength between pill consumption and eumenorrheic subjects $(p=0.46$ EF and $\mathrm{p}=0.16 \mathrm{ML})$ or pill withdrawal and eumenorrheic subjects $(p=0.41 \mathrm{EF}$ and $\mathrm{p}=0.05 \mathrm{ML})$ (table 4$)$, despite significant differences in the concentration of oestradiol and progesterone between groups (figs 1, 2). The concentration of oestradiol and progesterone was significantly higher (all $\mathrm{p}<0.05$ ) during the ML phase of the menstrual cycle compared with the EF phase of the menstrual cycle and pill consumption (7C) and withdrawal (5WD). Pill users were not stronger or weaker than their eumenorrheic counterparts. There were no significant differences in muscle strength between the EF and ML phases of the menstrual cycle $(\mathrm{p}=0.1)$.

\section{DISCUSSION}

In the present study, pill administration resulted in the downregulation of endogenous oestradiol and progesterone, to levels indicative of the menopause. ${ }^{7}$ Despite seven pill free days, endogenous concentrations of oestradiol and progesterone did not fluctuate. As all subjects experienced menstruation during their seven pill free days, it would appear that 
Table 3 Correlation coefficients between the strength parameters and the plasma hormone concentrations of endogenous oestradiol and progesterone

\begin{tabular}{|c|c|c|}
\hline Muscle function & Oestradiol & Progesterone \\
\hline $\begin{array}{l}\text { MVIF of the FDI } \\
\text { muscle (N) }\end{array}$ & $-0.290(0.063)$ & $-0.165(0.296)$ \\
\hline $\begin{array}{l}\text { Isokinetic extension } \\
1.04 \mathrm{rad} / \mathrm{s}(\mathrm{Nm})\end{array}$ & $-0.038(0.813)$ & $0.163(0.304)$ \\
\hline $\begin{array}{l}\text { Isokinetic flexion } \\
1.04 \mathrm{rad} / \mathrm{s}(\mathrm{Nm})\end{array}$ & $-0.312(0.045)$ & $-0.068(0.670)$ \\
\hline $\begin{array}{l}\text { Isokinetic extension } \\
2.09 \mathrm{rad} / \mathrm{s}(\mathrm{Nm})\end{array}$ & $-0.089(0.573)$ & $0.255(0.103)$ \\
\hline $\begin{array}{l}\text { Isokinetic flexion } \\
2.09 \mathrm{rad} / \mathrm{s}(\mathrm{Nm})\end{array}$ & $-0.084(0.597)$ & $-0.071(0.655)$ \\
\hline $\begin{array}{l}\text { Isokinetic extension } \\
4.19 \mathrm{rad} / \mathrm{s}(\mathrm{Nm})\end{array}$ & $-0.009(0.953)$ & $0.270(0.083)$ \\
\hline $\begin{array}{l}\text { Isokinetic flexion } \\
4.19 \mathrm{rad} / \mathrm{s}(\mathrm{Nm})\end{array}$ & $0.046(0.773)$ & $-0.030(0.851)$ \\
\hline $\begin{array}{l}\text { Isometric extension } \\
(\mathrm{Nm})\end{array}$ & -0.305 (0.049) & $0.231(0.141)$ \\
\hline $\begin{array}{l}\text { Isometric flexion } \\
(\mathrm{Nm})\end{array}$ & $-0.041(0.795)$ & $-0.209(0.184)$ \\
\hline \multicolumn{3}{|c|}{$\begin{array}{l}\text { Data are shown as Pearson and Spearmans correlation coefficients with } \\
\mathrm{p} \text { values below; } n=42 \text { ( } 14 \text { subjects over three phases). MVIF, maximun } \\
\text { voluntary isometric force; FDI, first dorsal interosseus muscle. There wer } \\
\text { no significant correlations between the strength parameters and the } \\
\text { plasma hormone concentration. }\end{array}$} \\
\hline
\end{tabular}

endogenous levels of oestradiol and progesterone did change, although not significantly $(\mathrm{p}>0.05)$. Under these conditions, maximum strength of the FDI or thigh muscles did not change significantly. These data suggest that pill use (consumption and withdrawal) does not affect the maximum force generating capacity of young healthy women.

Maximum voluntary isometric force of the FDI muscle was measured during two phases of the menstrual cycle with significantly different concentrations of circulating female reproductive hormones. The results showed no changes in strength across the menstrual cycle. Oral contraceptive users were not stronger or weaker than their eumenorrheic counterparts. This would suggest that the magnitude of downregulation (significant reduction at $\mathrm{p}<0.05$ ) experienced by oral contraceptive users was not sufficient to distinguish them (in terms of maximum isometric force production) from the "normal" cyclical population. The eumenorrheic subjects had significantly greater levels of oestradiol and progesterone during the ML phase of the menstrual cycle when compared with all phases of oral contraceptive use. We suggest that future research should also compare the dynamic strength of oral contraceptive users and eumenorrheic women, using an equal sample size (to increase the statistical power of the analysis).

The strength findings from this study indicate that consistently low levels of endogenous sex hormones caused by oral contraceptive use do not affect maximum force production in young healthy women, which has implications for both health and sports performance. Other investigations, using post-menopausal women, have also shown that chronic sex hormone deprivation does not affect muscle strength. Young et $a l^{24}$ found no difference in quadriceps strength in relation to cross sectional area (measured using ultrasound) between young and old women. Similarly, data from the Allied Dunbar National Fitness Survey ${ }^{25}$ demon- $^{26}$ strated that the age related decline in quadriceps and handgrip strength did not accelerate in women during the fifth decade (the average age of menopause in England). On reviewing those studies that have found an accelerated loss in strength coinciding with the menopause, ${ }^{1-7}$ the majority have not specified or documented post-menopausal status or the time course associated with changes in strength.
Table 4 Comparison of FDI strength (N) between the pill users and eumenorrheic subjects. There were no significant differences in strength between groups

\begin{tabular}{ll}
\hline Phase & Mean (SD) \\
\hline Pill consumption & $35.2(7.2)$ \\
Pill withdrawal & $34.6(7.4)$ \\
Early follicular & $28.2(4.3)$ \\
Mid-luteal & $30.9(7.5)$ \\
\hline
\end{tabular}

Consequently, the length of time over which oestrogen and progesterone are altered and the concentration of these hormones required to elicit changes in strength are unknown. Further research is necessary to confirm a direct relationship between low levels of reproductive hormones and diminished strength. In particular, a significant negative correlation between the concentration of oestrogen and progesterone (or years since menopause) and strength needs to be demonstrated.

Skelton et al found that post-menopausal women were significantly weaker than hormone replacement therapy (HRT) users. These authors defined post-menopausal status as having a serum oestradiol level $<50 \mathrm{pmol} / \mathrm{l}$. In the present study, the mean oestradiol concentration was 135.59, 156.27, and $128.00 \mathrm{pmol} / \mathrm{l}$ in $7 \mathrm{C}, 14 \mathrm{C}$, and 5WD, respectively. However, neither maximum dynamic or isometric force decreased under these circumstances.

During the menopause, levels of FSH, and to a lesser extent, LH, rise and are secreted in continuous quantities. Post-menopause, FSH and LH levels are increased by 10-15 fold and 3-5 fold respectively, compared with the levels found in the follicular phase of a pre-menopausal woman. As a result of oral contraceptive use, the concentration of LH and FSH declines. However, it is unlikely that the difference in LH and FSH levels between pill use and the menopause is responsible for the reported differences in strength production, as Greeves et $a^{27}$ found that muscle strength was not influenced by fluctuations in LH and FSH during in vitro fertilisation.

Exogenous, synthetic reproductive hormones (in particular HRT) have been shown to increase strength, ${ }^{357}$ therefore strength might have been expected to increase as a result of oral contraceptive administration and decrease following pill withdrawal. In the present study, pill withdrawal did not affect the concentration of oestradiol and progesterone or any strength measure. Differences in exogenous hormone concentration between pills and HRT may account for the disparity in results between this study and previous research showing increased strength following HRT administration. Conventional pills contain approximately $30 \mu \mathrm{g}$ and $250 \mu \mathrm{g}$ of synthetic oestrogen and progesterone, respectively, while HRT pills usually contain $625 \mu \mathrm{g}$ of exogenous oestrogen and 5-10 mg of exogenous progesterone. The effects of HRT on strength should be viewed with caution, as existing research is inconclusive. HRT has been shown to increase, ${ }^{357}$ maintain, ${ }^{2}$ or have no effect ${ }^{28-31}$ on a variety of strength measures. We are not aware of any literature at present that suggests that oral contraceptives (as a model of synthetic hormone supplementation) can affect performance in ways other than suppression of endogenous oestradiol and progesterone.

In agreement with this study, Sarwar et al ${ }^{8}$ showed that maximum strength was unaffected by pill use. These authors tested MVIF of the quadriceps and hand muscles every week over two cycles (including the seven pill free days). All subjects were taking a monophasic combined pill (20-35 $\mu \mathrm{g}$ of ethinyloestradiol and progestins in different doses). 


\section{What is already known on this topic}

- The exact effects of reproductive hormones on force production in women are unknown.

- Muscle strength has been shown to increase, decrease, or remain unchanged during the menstrual cycle and following the menopause, as a result of hormone replacement therapy and oral contraceptive use.

\section{What this study adds}

- The present study is the first to measure levels of endogenous oestradiol and progesterone and directly relate them to muscle strength in oral contraceptive users and eumenorrheic subjects.

- The findings from this study suggest the oestradiol and progesterone do not affect maximum force production in young sedentary women.

Similarly, Phillips et al found no cyclical changes in MVIF of the adductor pollicis muscle in subjects using a non-specified pill.

In the present study, a large variation (reflected by the SD values) in hormone concentration was found in both subject groups (pill users and eumenorrheic women). Despite standardising blood collection, the large variation in hormone levels during the menstrual cycle could be due to ultradian patterns $(<24 \mathrm{~h})$ of hormone secretion. The variation in the concentration of endogenous oestradiol and progesterone in the pill group is likely to reflect the different pills consumed. Although all pill users ingested a monophasic, standard strength, combined pill, the exogenous oestrogen and progestogen content ranged from 30-35 $\mu \mathrm{g}$ and $150-500 \mu \mathrm{g}$ respectively. In order to limit this effect, future studies should employ single type pill users only.

In conclusion, the administration or withdrawal of exogenous reproductive hormones caused by oral contraceptive use had no effect on maximum dynamic and isometric strength of the quadriceps and hamstring muscles, or on maximum isometric strength of the FDI muscle. This suggests that oral contraceptive use does not affect the maximum force generating capacity of young women. Moreover, chronic downregulation of endogenous oestrogen and progesterone levels did not distinguish young women from their eumenorrheic counterparts in terms of muscle function, and suggests that the decline in muscle strength seen following the menopause may not be sex hormone dependent. Future research should investigate the effect of oral contraceptive use on other strength and performance based parameters (such as muscle fatigability/endurance trials) and various health measures (such as bone mineral density) so that specific recommendations can be made to the pill user.

\section{Authors' affiliations \\ K J Elliott, University of Brighton, Brighton, UK \\ N T Cable, T Reilly, John Moores University, Liverpool, UK \\ Conflict of interests: none declared}

\section{REFERENCES}

1 Calmels $\mathbf{P}$, Vico L, Alexandre $\mathrm{C}$, et al. Cross-sectional study of muscle strength and bone mineral density in a population of 106 women between the ages of
44 and 87 years: relationship with age and menopause. Eur J Appl Physiol 1995;70:180-6.

2 Greeves JP, Cable NT, Reilly T, et al. Changes in muscle strength in women following the menopause: a longitudinal assessment of the efficacy of hormone replacement therapy. Clin Sci 1999;97:79-84.

3 Heikkinen J, Kyllonen E, Kurttila-Matero E, et al. HRT and exercise: effects on bone density, muscle strength and lipid metabolism. A placebo controlled 2year prospective trial on two estrogen-progestin regimens in healthy postmenopausal women. Maturitas 1997;26:139-49.

4 Onambele NGL, Skelton DA, Bruce SA, et al. Follow-up study of the benefits of hormone replacement therapy on isometric muscle strength of adductor pollicis in postmenopausal women. Clin Sci 2001;100:421-2.

5 Phillips SK, Rook KM, Siddle NC, et al. Muscle weakness in women occurs at an earlier age than in men, but is preserved by hormone replacement therapy. Clin Sci 1993;84:95-8.

6 Rutherford OM, Jones DA. The relationship of muscle and bone loss and activity levels with age in women. Age Ageing 1992;21:286-93.

7 Skelton DA, Phillips SK, Bruce SA, et al. Hormone replacement therapy increases isometric muscle strength of adductor pollicis in post-menopausal women. Clin Sci 1999;96:357-64.

8 Sarwar R, Niclos BB, Rutherford OM. Changes in muscle strength, relaxation rate and fatigability during the human menstrual cycle. J Physiol 1996;493:267-72.

9 Phillips SK, Sanderson AG, Birch K, et al. Changes in maximal voluntary force of human adductor pollicis muscle during the menstrual cycle. J Physiol 1996;496:551-7.

10 Wirth JC, Lohman TG. The relationship of static muscle function to use of oral contraceptives. Med Sci Sports Exerc 1982;14:16-20.

11 De Valk-de Roo GW, Netelenbos JC, Peters-Muller IRA, et al. Continuously combined hormone replacement therapy and bone turnover: the influence of dydrogesterone dose, smoking and initial degree of bone turnover. Maturitas 1997;28: 153-62.

12 Bonen A, Ling WY, Maclntyre KP, et al. Effects of exercise on serum concentrations of FSH, LH, progesterone, and estradiol. Eur J Appl Physiol 1979;42:15-23.

13 Lanigan C, Howes TQ, Borzone G, et al. The effects of beta(2)-agonists and caffeine on respiratory and limb muscle performance. Eur Respir J 1993;6:1192-6.

14 Reichman ME, Judd JT, Longcope C, et al. Effects of alcohol-consumption on plasma and urinary hormone concentrations in premenopausal women. J Natl Cancer Inst 1993;85:722-7.

15 York JL. The drinking day as a unit of exposure in the epidemiology of alcohol-related medical disorders. Alcohol 1998;16:231-6.

16 Reilly T. Human circadian rhythms and exercise. Crit Rev Biomed Eng 1990;18:165-80.

17 Crosignani PG, La Vecchia C. Hormonal contraception. In: Dooley MM, Brincat MP, eds. Understanding common disorders in reproductive endocrinology. New York: John Wiley and Sons Ltd, 1994:123-43.

18 Beltran Niclos B, Welsh L, Sarwar R, et al. Gender and age comparisons of the contractile properties of human quadriceps muscle. J Physiol 1995;483:131P.

19 Rutherford OM, Jones DA. Contractile properties and fatigability of the human adductor pollicis and first dorsal interosseus: a comparison of the effects of two chronic stimulation patterns. J Neurol Sci 1988;85:319-31.

20 Tanaka M, McDonagh MJN, Davies CTM. A comparison of the mechanical properties of the first dorsal interosseus in the dominant and non-dominant hand. Eur J Appl Physiol 1984;53:17-20.

21 Elliott KJ, Cable NT, Reilly T, et al. Effect of menstrual cycle phase on the concentration of bioavailable oestradiol and testosterone and muscle strength. Clin Sci 2003;105:663-9.

22 Elliott KJ, Sale C, Cable, NT. The effects of 8-weeks resistance training and 8weeks detraining on muscle strength and blood lipid profiles in postmenopausal women. Br J Sports Med 2002;36:340-4.

23 Landgren BM, Unden AL, Diczfalusy E. Hormonal profile of the cycle in 68 normally menstruating women. Acta Endocrinologica 1980;94:89-98.

24 Young A, Stokes $M$, Crowe $M$. Size and strength of the quadriceps muscles of old and young women. Eur I Clin Invest 1984;14:282-7.

25 Activity and Health Research. Allied Dunbar National Fitness Survey: main findings. London: Sports Council and Health Education Authority, 1992.

26 Activity and Health Research. Allied Dunbar National Fitness Survey: main findings. London: Sports Council and Health Education Authority, 1994.

27 Greeves JP, Cable NT, Luckas MJM, et al. Effects of acute changes in oestrogen on muscle function of the first dorsal interosseus muscle in humans. J Physiol 1997;500:265-70.

28 Armstrong AL, Oborne J, Coupland CAC, et al. Effects of hormone replacement therapy on muscle performance and balance in postmenopausal women. Clin Sci 1996;91:685-90.

29 Bassey EJ, Mockett SP, Fentem PH. Lack of variation in muscle strength with menstrual status in healthy women aged 45-54 years: data from a national survey. Eur J Appl Physiol 1996;73:382-6.

30 Seeley DG, Cauley JA, Grady D, et al. Is postmenopausal estrogen therapy associated with neuromuscular function or falling in elderly women? Arch Int Med 1995;155:293-9.

31 Taaffe DR, Villa ML, Delay R, et al. Maximal muscle strength of elderly women is not influenced by oestrogen status. Age Ageing 1995;24:329-33. 


\section{LETTER}

\section{Quadriceps assessment in professional soccer players}

Clinical examination of the knee involves eliciting certain signs that may indicate the presence of knee pathology. One such is quadriceps wasting. This occurs most commonly as the result of disuse or from a painful or unstable lesion of the knee.

Comparing the circumference of the thighs at a set level above the patella is the standard method of testing for atrophy. ${ }^{12}$ This, however, assumes that the thighs are normally of equal circumference. ${ }^{3}$

It has been noted by the senior author (GCB) that, in children, the non-kicking leg seemed often to be larger than the other. We aimed to test this observation in a prospective study of a group of professional soccer players.

Patients and methods

A population of 38 players took part in the study, all from professional clubs in Edinburgh. None had a recent injury.

All the participants had both thigh circumferences measured at a point $15 \mathrm{~cm}$ above the proximal pole of the patella. In each case the subject was standing and the quadriceps relaxed. The trial was blinded in that the investigator making the measurements did not know which foot was predominant. To minimise error, all measurements were carried out by one investigator. The foot preference of each player was recorded on a sliding scale and later converted into a percentage. All expressed a preference for one foot over the other.

\section{Results}

Complete data were available for 38 players. Of those with a preference for their right foot, $95 \%(\mathrm{n}=20)$ had a larger left thigh (range $1.5-2 \mathrm{~cm}$ ). The difference was less striking in the group with left foot preference, with $62.5 \%(\mathrm{n}=8)$ having a larger right thigh (range $1.5-2 \mathrm{~cm}$ ).

These differences were analysed using the Wilcoxon signed rank test (Minitab Release 12.21: www.minitab.com). The test showed that the differences were significant $(\mathrm{p}=0.001)$ with a $95 \%$ confidence interval for the median difference in thigh circumference (non-dominant) of 0.5 to $1.0 \mathrm{~cm}$.

\section{Discussion}

We conclude that there is strong statistical evidence that the thigh circumference of the non-dominant leg is significantly greater than that of the dominant leg by between 0.5 and $1 \mathrm{~cm}$. This supports the hypothesis that professional soccer players have larger quadriceps in their non-kicking legs.

This should be taken into account when examining the legs of sportsmen and women.
There is much scope for further investigation into this trend, particularly as to whether it occurs in other sports, and at what level of participation this effect becomes apparent.

\section{Acknowledgements}

We would like to thank the players of Heart of Midlothian and Hibernian Football Clubs who kindly took part in the study.

S J Bennet, P B O'Donohoe Edinburgh University Medical School, Edinburgh, Scotland, UK

D Young

Research and Development Office, Royal Hospital for Sick Children, Glasgow, Scotland, UK

G C Bennet

Department of Orthopaedic Surgery, Royal Hospital for Sick Children, Glasgow

Correspondence to: S J Bennet, Edinburgh University Medical School, Edinburgh, Scotland, UK; simonbennet@hotmail.com

No formal ethical approval was required for this study.

doi: 10.1136/bism.2004.015933

Competing interests: none declared

\section{References}

1 McRae R. Clinical orthopaedic examination 3rd ed. Edinburgh: Churchill Livingstone, 1990

2 Salter RB. Textbook of disorders and injuries of the musculoskeletal system, 3rd ed. Baltimore: Williams and Wilkins, 1999:65-8.

3 Robben SG, Lequin MH, Meradj $M$, et al. Atrophy of the quadriceps muscle in children with a painful hip. Clin Physiol 1999:19:385-93.

\section{BOOK REVIEWS}

\section{Exercise physiology: people and ideas}

Edited by Charles M Tipton. Oxford University Press, 2003, £69.50, pp 510, hardcover. ISBN 0195125274

It is not often that one finds a systematic review of science history that reads like an exciting non-fiction novel, but Exercise physiology is just that. In fewer than 500 pages, a surprisingly in-depth story of the growth in the understanding of exercise physiology science is told. The authors trace the exciting journey of discovery-a journey that at times was painfully slow when centuries passed by in which no contributions to the field were made, and at other times when discovery and new ideas emerged with breath taking speed.

The splendid introductory chapter, Ancient and early influences, traces the development of the thought, ideas, and study of exercise physiology from Hippocrates to Austin Flint.
The physiological concepts of Galen, the first sports medicine physician (he was physician to the gladiators at Pergamum), are described in depth-concepts that governed medical practice for nearly 1500 years. Among others whose ideas are described are Vesalis, Avencia, Descartes, Willis, and Boyle. Early thoughts on the training of athletes and of exercise physiology were confirmed or disproved and discarded. The chapter author skillfully fleshes out concepts and elucidates controversies.

As edifying the reading of the introduction is, the reader will find the chapters organised around major body systems physiology just as enlightening. Editor Charles Tipton, who also contributed the chapter on the autonomic nervous system, brought together 19 other distinguished scientists as chapter authors, several of whom have received the Olympic Prize in Sports Sciences and several others the ACSM Honor Award. The chapters trace the development of the science of exercise in the neuromuscular, cardiovascular, respiratory, autonomic, oxygen transport, aerobic metabolic, anaerobic metabolic, endocrine, temperature regulation, renal, and gastrointestinal systems. Among the scientists whose work is discussed in these later chapters are Henneman, Burke, A V Hill, Fick, Starling, Guyton, Asmussen, Astrand, Cannon, Zuntz, Selye, Ingle, Costill, and Lambert.

Each chapter includes a frank discussion of controversy and ideas with a skilful distillation of various conclusions. A bonus is the nearly encyclopaedic list of references, 1876 in all, a treasure of literature review.

The latest in the People and ideas series of the American Physiological Society, Exercise physiology is a superbly organised and splendidly written history of exercise physiology. The text will be a useful addition to the library of those sports medicine professionals interested in the history of the science of exercise.

\section{Rating}

- Presentation

- Comprehensiveness

$18 / 20$

- Readability

$18 / 20$

- Relevance

$18 / 20$

- Evidence basis

$20 / 20$

- Total

$94 / 100$

\section{McMinn's colour atlas of human anatomy}

Edited by P H Abrahams, S C Marks Jr, R T Hutchings. London: Mosby, £38.99, pp 378, softcover. ISBN 0723432120

Back in the late 70s, when Gray's and Grant's anatomy atlases ruled supreme for my 
vintage going through medical school, this text would have been a hit on the medical bookshop shelves: over 350 pages of layered real photo images of cadavers beautifully numbered, indexed, and with useful undergraduate level clinical text at the end of each chapter.

For students of medicine and other undergraduate areas, this is a whole atlas of human anatomy, not just limited to the musculoskeletal system. So for those looking purely for a musculoskeletal anatomy text, this would not be the most appropriate; a lot of pages-for example, those covering abdominal viscera-might never be perused.

Bony anatomy is, however, well covered, including muscle attachments, although illustrated drawings without descriptive text has its drawbacks; in many cases, one has to look at more than one page to follow a whole muscle group from origin to insertion. In areas of very complex anatomy especially, such as the axilla/brachial plexus region, more text would have helped the reader to understand the anatomical relations of structures to each other. But the CD ROM comes into its own here: seven regions in detail where one can scroll through the images from superficial to deep layers (including the detailed courses of arteries, veins, and nerves), rotate the images to view at all angles, enlarge them, add and remove muscle layers off the models, and rotate limbs around to follow dermatomal distributions on surface anatomy. It certainly would have made learning clinical anatomy for exam purposes a whole lot easier 20 years ago and will now become a very useful teaching aid in my office for patients and visiting students alike.

Who is the book pitched at? In the preface, the authors say that it is aimed at students of human anatomy including medicine, dentistry, physiology, and occupational therapy students, but postgraduate students in orthopaedic surgery and sports medicine would find aspects of this very useful.

The clinical notes at the end of each chapter tend to be pitched very much at an undergraduate level-for example, defining "olecranon bursitis" and "rotator cuff tear" in the "Upper Limb clinical notes". The atlas pictorial pages along with the CD ROM would be extremely useful in any clinician's office, however. You will have your patients "wowing" at this representation of human anatomy. "Archibald", the full skeleton who's been camped in my office for the past 15 years, might be moving out! The CD ROM occupies much less space and comes with the ability to show off much more than just bony anatomy!

\section{Rating}

- Presentation

- Comprehensiveness

- Readability

$15 / 20$

- Relevance

$14 / 20$

- Evidence basis Not applicable

- Total $59 / 80$

R Highet

\section{Rehabilitation of sports injuries: scientific basis}

Edited by Walter R Frontera. London: Blackwell, 2003, £65.00, pp 326, hardcover. ISBN 0632058137

Do not buy this book if you are seeking the latest word on hamstring rehabilitation or current concepts in the management of multidirectional instability of the shoulder in athletes. As the title implies, this book addresses the scientific basis of the rehabilitation of sports injuries. As such it is relatively dry and will not have wide appeal for those seeking guidance in their practice of rehabilitation of the injured athlete. It does, however, provide a good review of the scientific basis of tissue healing and addresses the sound underpinning principles of rehabilitation and commonly used modalities.

As with any multiauthor edited text, the quality of individual chapters is variable. I was particularly surprised, and indeed disappointed, that the chapter addressing tissue healing and repair of bone and cartilage barely mentioned stress fractures and instead concentrated on the healing and management of traumatic and long bone fractures, which is perhaps of greater interest to orthopaedic trainees than practicing sports medicine physicians or physiotherapists. With the notable exception of a chapter addressing flexibility and joint range of motion, this book is short on presenting the evidence base for rehabilitation. Having read the book, I found myself longing for the follow up volume to this addition (should they choose to publish one) entitled Rehabilitation of sports injuries: practical guidance and the evidence base. As a practicing sports medicine physician, my interest is in the practical issues of rehabilitation and cutting edge techniques as it is these that will help my patients, albeit underpinned by good scientific principles. This book does provide a comprehensive review of scientific principles, but I fear its readership will be limited as there is only a single chapter addressing functional rehabilitation.

\section{Rating}

- Presentation $15 / 20$

- Comprehensiveness

- Readability

$12 / 20$

- Relevance $13 / 20$

- Evidence basis $10 / 20$

- Total
M E Batt

Clinical application of neuromuscular techniques: volume 1 the upper body

Edited by Leon Chaitow, Judith Walker DeLaney. Churchill Livingstone, 2000, £45.99, pp 469, hardcover. ISBN 0443062706

As stated on page 2, imagine removing all the organs of the body, leaving only the connective tissue. What would remain would still resemble the human form, and its function could be readily appreciated, whereas doing the opposite would leave an unrecognisable collection of organs, devoid of form or function. Although there is little scientific evidence presented, such as controlled therapeutic trials, as to why these techniques are effective, this impressive first volume lights the way for practitioners of muscle energy techniques (METs), well known here in Australia, and neuro-muscular technique or NMT (Europe)/neuro-muscular therapy (America). It covers in great detail the entire background to the collection of manual techniques concerned with changes to the connective tissue, including fascia, muscle, joint, bone, and nerve, due to injury and disease. The first volume begins with chapters describing the function and dysfunction of the connective tissue and fascial system, muscles, reporting systems and the brain, patterns of dysfunction, myofascial trigger points, inflammation and pain, assessment, treatment and rehabilitation, modern NMT and associated modalities. Text boxes interspersed in the chapters summarise the broad range of previous authors' work in these areas. This is followed by a regional consideration of clinical assessment and treatment techniques in the cervical region, cranium, shoulder/arm /hand, and thorax.

NMT is described in both European (Lief's techniques, which are fundamentally "manual application of specialised pressure and strokes ...applied by finger or thumb contact") and American versions (manual glides and pincer compression assessing for taut tissue bands and treatment using glides and flat or pincer compression).

Associated modalities include myofascial release (MFR), MET, and other positional release techniques (PRTs), strain-counterstrain, proprioceptive neuromuscular facilitation (PNF) and other stretching, which have in common the concept of moving the limb or affected tissues "...away from the resistance barriers towards a position of comfort..." as follow up to the manual treatment.

In the clinical applications chapters, the functional anatomy is described, as are common causes of dysfunction, such as whiplash. Every muscle of the region is described systematically in terms of attachments, innervation, muscle type, function, synergists, antagonists, trigger point locations, and patterns of complaint. This is followed by a description of NMT, MFR, and MET treatment options.

There are very few good references on MET, Chaitow having written or co-written most of them previously, and this text helps to integrate MET with the other manual techniques in a logical way. Impossible to summarise in a book review because of its depth of detail and scope, this book could serve the neuro-musculo-skeletal practitioner as both a reference text and practical technique manual. It is formulaic in its approach, which makes it simple to use despite its size. Although there are few specific details on sports injury, sports medicine practitioners and physical therapists would be well advised to have this book in their professional library.

\section{Rating}

- Presentation $17 / 20$

- Comprehensiveness

- Readability

$18 / 20$

- Relevance

$15 / 20$

- Evidence basis

$15 / 20$

- Total 


\section{Physical therapies in sport and exercise}

Edited by G S Kolt, L Snyder-Mackler. Published by Churchill Livingstone, 2003, $£ 60.00$, hardcover, pp 623. ISBN 0443071543

Physical therapies in sports and exercise, as the name suggests, is sports medicine from a physical therapy perspective. As with all of these types of book, it tries to cover everything, draws on clinicians and researchers from around the globe, and succeeds well in giving a general guide. It is a mix of strong and concise anatomical review, general concepts within sports and exercise, regional injury management, other active groups, and a section on medical issues.

The editors make the point early on that there is a dearth of evidence for the techniques and approaches we use in physical therapies within sport. The stated aim is to "provide a logical approach to the management of sport and exercise injuries that considers the available evidence for the efficacy of a variety of management approaches." This book tries to use supporting evidence to develop the ideas presented, but despite this, often draws on the anecdotal clinical experience of the authors. How else would they get the notion that short runners tend to overstride ( $p$ 250)? If the book had stuck to the stated aim of evidence based statements, we would only have a book half the size and a lot more short athletes with facet joint problems.

This approach is demonstrated beautifully in the chapter on patellofemoral pain syndrome (PFPS). Sections outlining the theory, evidence, and practice of this condition provide a well structured layout. The authors of this chapter are able, in this way, to present the anecdotal evidence, the clinical findings, and acknowledge where further research needs to be done. It highlights that the evidence based techniques we now use for PFPS are the same techniques we used in our clinics 5-10 years ago which were then not evidence based! Without wishing to delve too much into the debate of "evidence based sports medicine", I found that this chapter, in general, rides the line well between providing the evidence for the management and acknowledging that other areas used within the overall program need to be further investigated.

There was quite a discrepancy in the layout and structure of the other chapters. It was difficult to know the focus. The clinician looking for prescriptive rehabilitation techniques and programmes would do well to look in the elbow chapter, but if looking for similar protocols for hamstring injuries, the clinician would be disappointed.

Similarly, the amount of space allocated to a region was inconsistent, and this was probably due to how much evidence was available or the interest/knowledge of the author. Whereas there were 20 pages devoted to patellofemoral joint pain, there was a page and a half on groin pain in its entirety, including just a few paragraphs on osteitis pubis. The multifactorial nature of hamstring pain and the management of this condition were given cursory consideration, despite the fact that these conditions often present the biggest challenge to the practitioner.

The last chapter makes an interesting read and attempts valiantly to roll years of academic and clinical sports physician training into a few short pages. Within sports medicine, it is all too easy to get caught up in addressing the musculoskeletal issues, and forget the impact of common (and not so common) medical issues on the elite athlete. As primary contact practitioners, we have to ensure we have a strong multidisciplinary team around us. I would have liked to see a bit more attention paid to the multidisciplinary team and the physical therapists role within it.

There is some really useful information and up to date evidence based thinking within this text. For the primary clinician on the field of play, however, to rely on the knowledge in this book as the sum total of his/her arsenal would be to be left wanting. On balance, I can recommend Physical therapies in sport and exercise as an invaluable adjunct to the sports clinician's library.

\section{Analysis}

- Presentation $17 / 20$

- Comprehensiveness

$14 / 20$

- Readability $18 / 20$

- Relevance $18 / 20$

- Evidence basis

$16 / 20$

- Total

$83 / 100$

\section{CALENDAR OF EVENTS}

\section{UK Radiological Congress 2005 (UKRC 2005)}

6-8 June 2005, Manchester, UK

The UK Radiological Congress (UKRC) meeting will encompass the medical, scientific, educational, and management issues that are of interest and relevance to all those involved in the diverse fields of radiological sciences and oncology.

The UKRC provides a forum in which to bring together clinicians, scientists, radiographers, technicians, and other professionals to present and discuss the latest developments and challenges in diagnostic imaging, radiotherapy, and allied radiological sciences.

Key subjects to be covered include: diagnostic radiology; ultrasound; nuclear medicine; interventional radiology; veterinary radiology; emerging technologies; image analysis; computer applications; PACS; radiobiology; radiological physics; management \& audit; computed tomography; magnetic resonance; equipment development.

Expected attendance (conference and exhibition): 4000

Further details: UKRC 2005 Organisers, PO Box 2895, London WIA 5RS, UK; Website: Www.ukrc.org.uk; Fax: +44 (0)20 7307 1414; Conference tel: +44 (0)20 7307 1410, Email: conference@ukrc.org.uk; Exhibition tel: +44 (0)207307 1420, Email: exhibition@ukrc. org.uk

\section{1st World Congress on Sports Injury}

\section{Prevention}

23-25 June 2005, Oslo, Norway

This congress will provide the world's leading sports medicine experts with an opportunity to present their work to an international audience made up of physicians, therapists, scientists, and coaches. The congress will present scientific information on sports injury epidemiology, risk factors, injury mechanisms and injury prevention methods with a multidisciplinary perspective. Panel discussions will conclude symposia in key areas providing recommendations to address the prevention issue in relation to particular injuries and sports.

Further details: Oslo Sports Trauma Research Centre and Department of Sports Medicine, University of Sport and Physical Education, Sognsveien 220, 0806 Oslo, Norway. Email: 2005congress@nih.no; website: www.ostrc.no

\section{Osteosynthese International 2005}

15-17 September 2005, Curiohaus, Hamburg Congress-Chairman: Johannes M. Rueger, M.D., Professor and Chair Topics:

- Innovations in intramedullary osteosynthesis

- New frontiers in osteoporosis and fracture treatment

- Current trauma research

- Special topic: Recent development in pelvic and acetabular fractures

Abstract submission deadline: 31 March 2005

Further details: INTERCONGRESS GmbH, Martin Berndt, Düsseldorfer Str. 101, 40545 Düsseldorf-Germany. Tel: +49 $211585897-$ 80; fax: +49 211 585897-99; email: martin. berndt@intercongress.de; website: www. osteoint2005.de

\section{4th European Sports Medicine Congress}

13-15 October 2005, Lemesos, Cyprus

Further details: Email: pyrgos.com@cytanet. com.cy

\section{BASEM Conference 2005}

10-12 November 2005, Edinburgh, Scotland Further details: Email: basemoffice@ compuserve.com

\section{BASEM Conference 2006}

5-7 October 2006, Oxford, UK

Further details: Email: basemoffice@ compuserve.com

\section{CORRECTION}

doi: 10.1136/bjsm.2004.009886corr l

Elliott K J, Cable N T, Reilly T. Does oral contraceptive use affect maximum force production in women? (Br J Sports Med 2005; 39:15-9). The correspondence and affiliation details were published incorrectly in this paper. The correct address is: Dr Kirsty J Elliott, Applied Biomedical Sciences Research Group, GKT School of Biomedical Sciences, Shepherds House, Guys Campus, London SEl IUL; email: kirsty.elliott@kcl.ac.uk

We apologise for this error. 